\title{
A Vila Olímpica da Maré e as políticas públicas de esporte no Rio de Janeiro: um debate sobre a relação lazer, esporte e escola*
}

\begin{abstract}
Resumo: A partir do debate da dimensão educativa nas vivências culturais de lazer, o presente texto busca discutir como se deu a interação Vila Olímpica da Maré (VOM) e as escolas que se relacionavam com ela no processo de implementação dessa política pública de esporte e lazer da Prefeitura do Rio de Janeiro. Como se deram às relações entre Escolas e VOM? Que concepções de educação, esporte e lazer estiveram presentes nesse processo? Qual a dimensão político-pedagógica desses encontros?

Palavras-chave: educação, lazer, esporte e Vila Olímpi-
\end{abstract} ca da Maré.

\section{As equipes se preparam para entrar em campo}

Embora seja lugar comum afirmar que a educação é um processo mais amplo que a escolarização, não têm sido muito recorrentes debates acerca da dimensão educativa em outros espaços que não a escola. Nesse processo, as vivências culturais de lazer ocupam papel importante. Ainda que considerando as díspares maneiras que as diversas classes sociais vivenciam seus momentos de lazer, não podemos negar ser esta uma dimensão fundante da vida humana.

As vivências culturais de lazer se apresentam como educativas por representarem possibilidades de encontros com a produção cultural da humanidade. Neste processo, a atuação da escola tem sido constantemente debatida. Face isso, algumas questões insistem em se fazer presentes. Como tem sido a relação entre o processo de escolarização e o lazer? Como os diversos, e muitas vezes, antagônicos

* Este texto é baseado na dissertação de mestrado intitulada "Vila Olímpica da Maré e as Políticas Públicas de Esporte em Favelas no Rio de Janeiro: novas dinâmicas e as Politicas Públicas de Esporte em Favelas no Rio de Janeiro: novas dinâmicas da relação Estado e sociedade civil em tempos neoliberais", defendida no Programa de Pós-graduação em Educação da UFF/RJ em 2004, que contou com financiamento da CAPES. Ver MELO (2005)

Movimento, Porto Alegre, v. 11, n. 3, p. 89-106, setembro/dezembro de 2005 
projetos políticos de formação humana nas escolas brasileiras têm enfrentado a formação das novas gerações para uma vivência crítica e criativa do lazer? Os processos de escolarização podem influenciar na vivência do lazer? E o inverso, ou seja, como os momentos de lazer incidem no processo de escolarização?

Tendo em vista tais pontos, o presente texto busca discutir como se deu a interação Vila Olímpica da Maré (VOM) e as escolas que se relacionavam com ela no processo de implementação dessa política pública de esporte e lazer da Prefeitura do Rio de Janeiro. Para tal, foram analisados documentos oficiais da VOM e da Prefeitura. Também foram realizadas entrevistas com seus principais representantes, além da experiência como docente durante três anos no programa.

\section{Começa o jogo ou sobre a relação lazer, educação e escola}

Este trabalho é amplamente fundamentado no referencial teórico marxista, dialogando principalmente com as formulações e método de Antonio Gramsci. Assim, buscou-se compreender tais ações no bojo do amplo processo de luta entre as classes sociais objetivando a conquista da hegemonia. As formulações do marxista italiano ajudam-nos a esclarecer a dimensão educativa dessa nova configuração política da sociedade civil. O autor nos chama a atenção para a dimensão educativa do Estado capitalista, lembrando da ampliação do conceito de Estado, sendo este constituído pela sociedade civil e pelo aparelho estatal, ou Estado restrito. Assim, todo Estado procura criar, difundir e manter formas específicas de sociabilidade conforme o projeto societário do bloco no poder, assumindo uma função claramente educativa. Esse projeto educativo tem por objetivo, então, "[...] adequar a 'civilização' e a moralidade das mais amplas massas populares às necessidades do aparelho econômico de produção e, portanto, de elaborar também fisicamente tipos novos de humanidade" (GRAMSCI, 2001, p. 23).

Esse projeto de conformação das massas ao projeto do bloco no poder é sempre mediado pela unidade dialética entre estrutura e superestrutura, na formação/emergência de um novo bloco histórico. Com isso, "[...] o Estado deve ser concebido como 'educador' na medida em que tende precisamente a criar um novo tipo ou nível de civilização" (idem, p. 28). Por isso, certas práticas políticas são incentivadas, outras coibidas ou então seriamente desqualificadas,

Movimento, Porto Alegre, v. 11, n. 3, p. 89-106, setembro/dezembro de 2005 
promovendo um processo educativo de resistência a umas e aceitação a outras, mediadas pelas resistências advindas de outras classes sociais e suas frações.

É ponto pacífico que as vivências culturais de lazer trazem em si importantes dimensões educativas. Com isso, estamos afirmando que essa dimensão educativa pode se relacionar a diferentes projetos educativos e conseqüentemente a diferentes projetos de sociedade. Mesmo um projeto educativo que contemple a relação lazer e educação unicamente do ponto de vista de disseminação de uma lógica de consumo fugaz de práticas de lazer não deixa de ser educativo, ainda que considerado sob o ponto de vista de perpetuação e naturalização das relações de mercado.

Essa consideração visa enfrentar uma certa idealização do "termo" educativo. É comum notarmos que a simples menção que alguma prática cultural seria "educativa", lhe confere uma dimensão de prática social "naturalmente" relacionada à ampliação da visão de mundo dos envolvidos ou mesmo aproximando de uma tendência que se encerra em si. Lembrando um comercial de outros tempos: "se é educativo, é bom".

Não vemos nisso nenhum debate moral sobre se uma prática de lazer seria boa ou má, e sim sua vinculação com projetos de sociedade em disputa. Não por acaso Gramsci (2001) nos lembra que toda relação de hegemonia é uma relação pedagógica, a partir do consenso ativo e/ou passivo obtido do conjunto da população, ou pelo menos da uma maioria significativa, sendo este consenso sempre provisório, demandando estratégias permanentes de conquista e/ou manutenção. Nesse processo, as vivências culturais de lazer obtêm uma posição de destaque, tanto na conservação quanto na possível introdução de novas relações sociais na disputa pela hegemonia, podendo influir na dinâmica de organização da sociedade.

Desconsidera-se que os processos de disseminação das relações sociais de produção existência fundadas na lógica capitalista também se dão por meios educativos de difusão de sua concepção de mundo e projetos de sociedade, sobretudo, por mecanismos subliminares de produção de vontade, desejos e valores. A eternização do capitalismo como única forma de organizar a vida em sociedade também se dá através das práticas de lazer.

Como apontam as pesquisas reunidas em Neves (2005), as estratégias do capital, em sua nova fase, amplamente influenciada por um neoliberalismo de novo tipo, ou terceira via, para educar consenso da população, passam pelo desenvolvimento de novas

Movimento, Porto Alegre, v. 11, n. 3, p. 89-106, setembro/dezembro de 2005 
formas de socialização. Dentre essas, a promoção e disseminação de um individualismo como valor moral radical, um engajamento político não classista de participação, e também a divulgação da noção ampliada de auto-responsabilização pela reprodução das condições sociais individuais e do grupo restrito a que estão inseridos os sujeitos sociais coloca intensos desafios aos movimentos e grupos políticos que buscam construir elementos contra-hegemônicos.

Trazendo Fredric Jameson (2001) para nossa conversa, podemos perceber que na atual fase do capitalismo, economia e cultura, talvez mais do que em outros momentos, se apresentam como dimensões dialéticas interdependentes. Assim, nos alerta que há uma dimensão cultural na economia, assim como a própria dimensão cultural torna-se também um elemento de circulação e produção de mercadorias, ainda que não diretamente ligado à produção clássica. O autor demonstra isso ao afirmar que as mercadorias diversas são compradas tanto por sua imagem quanto por sua utilidade imediata. Isso faz com que a propaganda hoje tenha dimensão importantíssima no capitalismo, difundindo tanto mercadorias, como concepções de mundo. Não apenas o produto em si é vendido. Junto dele seguem todos os seus valores. ${ }^{1}$

Por outro lado, a transformação da dimensão cultural em mercadoria altamente lucrativa e capaz de movimentar altas somas de capital faz com que em torno das práticas de lazer também se mova toda uma indústria. Assim, não é nada surpreendente a afirmação hoje do que se convencionou chamar de indústria do entretenimento como expressão de um ramo da economia voltado ao mundo das diversões. Assim, novamente Jameson (2001, p. 50) nos indica que a existência de batalhas e imposições dos EUA nos grandes acordos comerciais para que junto aos diversos produtos adquiridos pelos países periféricos sigam no pacote uma gama de produtos culturais como filmes, livros, programas de televisão. Inclusive isso se realiza nas negociações comerciais nos organismos internacionais como a OMC, o FMI o GATT entre outros. O marxista americano nos demonstra que os produtos culturais assumem a condi-

1 Isso nos faz lembrar de um comercial de cartão crédito vinculado a partir do ano 2004. Ao final da apresentaça das vantagens de se adquirir o cartão, o locutor 2004. Ao final da apresentação das vantagens de se adquirir o cartão, o locutor dizia: "Afinal, porque o mundo é agora". Nessa inocente frase se fazem presentes diversos elementos que nos ajudam a compreender a dinâmica da sociedade capitalista em nosso tempo, seja a apologia do consumo, seja uma presentificação da vida, onde não haveria perspectivas de futuro, que merecesse assim, engajar-se em mecanismos de lutas pelas melhorias das condições concretas de vida. O fetiche da mercadoria apontado por Marx nunca se mostrou tão atual.

Movimento, Porto Alegre, v. 11, n. 3, p. 89-106, setembro/dezembro de 2005 
ção de base e superestrutura no processo, encerrando em si tanto uma dimensão econômica, quanto uma dimensão política. ${ }^{2}$

Assim, o lazer se insere no interior dos conflitos existentes em nossa sociedade. As disputas de hegemonia entre as classes sociais e suas frações também se manifestam na existência de possibilidades diversas de vivências de lazer.

Outra afirmação que corrobora nossos argumentos relacionase com a disseminação de uma lógica consumista e fugaz de manifestações culturais no lazer. A cultura do fragmento, do pastiche, das relações sociais fugazes se apresenta tendo em conta supostas ampliações das possibilidades de vivência de lazer. São apresentadas diariamente diversas manifestações, mas cujo acesso a tais práticas culturais só se realiza sob a lógica de mercado (MASCARENHAS, 2004).

Nesse sentido, é emblemática a concepção ainda presente de ser o lazer uma necessidade supérflua no conjunto das necessidades humanas. Também se fazem presentes posições que alertariam para incongruência de se debater questões afeitas ao lazer, quando um conjunto significativo da população não tem sequer o que se comer.

Nesses casos, o lazer não é considerado direito social legítimo do conjunto da população, e sim um bem individual que alguns cidadãos poderiam dispor. Aos que estiverem muito ocupados tentando existir, isso se tornaria um luxo, ou uma demanda pequeno burguesa, que não consideraria "as reais necessidades do povo".

Tanto uma posição quanto outra, aparentemente oposta, se encontram na concepção da luta por ampliação de direitos como algo escalonado, onde haveria uma ordem de necessidades "mais urgentes", em detrimento de outras; ambas não consideram que num contexto de não aceitação do trabalho alienado para nenhum cidadão o lazer deixaria de ser algo "supérfluo", para compor o rol das ampliações de possibilidades de humanização, seja no contato com as diversas possibilidades artísticas, seja mesmo num processo de convivência com pessoas e grupos caros aos praticantes. Ou seja, tais demandas em si, não têm nada de menos importantes para uma vida de qualidade a nenhum morador humano deste planeta. Quanto às outras espécies não posso afirmar.

2 Jameson nos apresenta uma instigante polêmica acerca do papel do cinema de Hollywood nesse processo. "Ora, poderíamos argumentar que há uma boa razão para tudo isso: ou seja, que as pessoas gostam dos filmes de Hollywood possivelmente vão acabar gostando do modo de vida americano, se tiverem a possibilidade de atingi-lo" (p. 54).

Movimento, Porto Alegre, v. 11, n. 3, p. 89-106, setembro/dezembro de 2005 
Diante disso, a própria afirmação do lazer enquanto direito social, no qual todo o conjunto da população deveria ter acesso, fica extremamente frágil, mesmo com a afirmação positiva no corpo da lei. A luta por ampliação e/ou conquista do direito ao lazer insere-se assim numa luta pelo questionamento do atual modelo de sociedade, indicando a necessidade de ações que refundem a existência humana em torno de outra forma de organização social, já que o projeto capitalista tem provado cotidianamente sua capacidade de produção em massa de miséria e indigência.

A determinação de que cabe ao Estado prover meios para que a população possa dispor de vivências de lazer de qualidade nos leva a repensar a própria dinâmica da vida atual. Isto porque tal afirmação leva em conta todas as contradições referentes ao atual momento histórico, sobretudo, no que se refere às mudanças do papel do Estado.

Assim, pensar numa política pública de lazer nos impinge a propor uma nova forma de organização da cidade, onde o cidadão possa se relacionar com esta não apenas do ponto de vista de sua utilidade no processo de auto-exploração de sua capacidade; não apenas enquanto gerador de mais valia e acumulação de capital; enquanto eterno "transeunte".

Claro que tais palavras soam como devaneio no âmbito do atual momento. Como pensar tais questões no processo de desemprego e subemprego em massa, bem como os contínuos processos de precarização do trabalho, o qual tem sido submetida grande contingente da classe trabalhadora? Como pensar uma dinâmica de tempo e de deslocamento do cidadão pela cidade que não seja unicamente marcada pela lógica de produtividade?

Sem dúvida, considerando a realidade inexorável, tais questões soam como devaneios. Mas ao problematizarmos essa mesma realidade, torna-se tarefa urgente pensar em possibilidades que ainda não se realizaram, sob o risco de reduzirmos a existência humana ao campo do possível, do imaginável. Sonharemos e lutaremos apenas por um mundo possível?

Sobre a relação lazer e escolarização cremos ser necessário uma visão que aborde tais processos de forma interdependente. Com isso, queremos resgatar a noção de que os processos culturais que ocorrem em momentos não escolares são centrais para os sentidos que a escolarização terá para os diversos grupos sociais. Nesse meio, as práticas de lazer vivenciadas pelos sujeitos escolares podem fornecer significativas pistas de seus interesses,

Movimento, Porto Alegre, v. 11, n. 3, p. 89-106, setembro/dezembro de 2005 
concepções de mundo, aspirações que no tempo escolar não conseguiram se fazer compreendidos pelos envolvidos. Como nos fala Miguel Arroyo (2001), esse "afastar" da escola pode ser uma excelente maneira de recuperarmos sua centralidade, já que não se trata de minimizarmos seu papel, apenas recolocá-lo sob novas bases.

Ainda dialogando com Arroyo (2002), temos um alerta que a redução do educativo ao escolar podem implicar na desconsideração de outros processos de socialização e aprendizado que ocorrem ao largo do processo de escolarização, que precisam estabelecer com essas relações de maior proximidade. Assim,

a compreensão das dimensões formadoras ou deformadoras que acontecem em outros espaços sociais nos ajuda a melhor entender a centralidade e os limites da educação escolar, da formação no trabalho, a socialização na família, na rua, nos grupos de juventude (ARROYO, 2002, p. 147).

Por outro lado, essa interdependência lazer e escola concebe esta última como uma instituição muito relevante na formação, incentivo e promoção de novas possibilidades de vivência do lazer por parte dos sujeitos que a freqüentam. Assim, as escolas podem ter função preponderante nesse sentido, sobretudo na sua própria consideração como um centro de lazer nos momentos não escolares, como fins de semana, férias. A escola como centro irradiador de manifestações culturais de lazer, além de representar ela mesmo um espaço de lazer como suas salas, pátios, quadras de esporte, salas de vídeo.

Podemos apontar para o fato de que fora da escola também se constroem sujeitos sociais. Nesse caso, esse "fora da escola" pode servir como metáfora já que há possibilidades de processos educativos não escolares ocorrerem dentro da escola. Amplia-se o sentido de educação, e mesmo o papel a ser desempenhado pela Escola.

Notamos um certo revolver de justificativas conservadoras ao abordar a importância do lazer, sobretudo para jovens pobres. Com o avanço da pobreza e uma maior visibilidade da violência urbana credita-se ao lazer o papel de redentor da juventude pobre, visto que poderia controlar os "impulsos" violentos e promover uma sociabilidade "civilizada". Com isso, passam a ser recorrentes menções a uma suposta capacidade que programas de lazer destinados aos jovens pobres teriam num eventual controle de violência e criminalidade.

Frente a isso, Paulo Carrano (2003) nos oferece questões que precisam ser relevadas. São comuns ações voltadas à juventude estarem diretamente relacionados à temática da violência, gerando quase que uma monocultura analítica, parafraseando um termo do autor.

Movimento, Porto Alegre, v. 11, n. 3, p. 89-106, setembro/dezembro de 2005 
Com isso, debates e proposições acerca da realidade da juventude se dão de forma “... apartada do contexto global da realização das sociedades contemporâneas. Muitos dos 'problemas' que são atribuídos aos jovens são, na verdade, elementos sociais e ideológicos que atravessam a totalidade das estruturas e relacionamentos sociais" (CARRANO, 2003, p. 131).

Seguindo essa trilha, Carrano (2003) nos possibilita ampliar a visão acerca de uma relação muitas vezes apresentada de forma imbricada. Assim, a tematização da juventude articulada à violência produziu visões restritas e lineares, embora ainda orientem muitas ações e políticas públicas que tem como alvo principal o jovem, sobretudo pobre.

As políticas públicas de lazer "precisariam" de outras justificativas que não apenas democratização do acesso/permanência. Não é difícil ouvir assertivas de que o jovem que pratica esporte, por exemplo, não se envolve com drogas; ou argumentos mais conservadores no que tange ao tempo livre, como sendo este a raiz de todos os males e problemas da juventude; "não tem tempo de pensar besteira"; "não fica fazendo o que não deve na rua"; "mente vazia oficina do diabo".

Por trás de argumentações como estas estão presentes componentes que há muito marcam algumas iniciativas que atendem os jovens pobres. Percebemos claramente a posição de que o jovem se envolveria com o crime por não ter outras coisas a fazer, indicando uma suposta linearidade entre falta de opções de lazer com o ingresso no mundo do crime, além de estabelecer uma espécie de relação causa/conseqüência. Assim, o esporte e o lazer seriam "antídotos perfeitos" para coibir tais práticas, uma espécie de analgésico social, sempre numa perspectiva conservadora de controle social. Essa concepção salvacionista tem se feito presente em diversos momentos (MELO, 2005).

\section{Segundo tempo ou lazer, escolas e Vila Olímpica da Maré}

A partir desse debate acerca de possíveis relações entre lazer, educação e escola, podemos problematizar como se deu a experiência da Vila Olímpica da Maré (VOM), uma política pública de esporte e lazer da prefeitura do Rio de Janeiro, implementada pela ONG União Esportiva Vila Olímpica da Maré (UEVOM) na favela carioca de mesmo nome.

Movimento, Porto Alegre, v. 11, n. 3, p. 89-106, setembro/dezembro de 2005 
A VOM inicia suas atividades no ano 2000, embora a mobilização e os debates sobre sua implementação marcam presença desde 1995. Inicialmente reivindicada pelo conjunto de associações de moradores da Maré, seu processo de efetivação representou a confluência entre visões de mundo entre diversos organismos na sociedade civil, como o VIVA RIO, o CENTEX/COPPE, com interlocução direta com a Prefeitura da Cidade do Rio de Janeiro (PMRJ). Além disso, conta também, desde o ano 2000, com financiamento da Petrobrás para a manutenção de suas atividades, inserindo-se assim na difusão da noção de responsabilidade social empresarial.

Desde sempre encampada como uma política pública da PMRJ, sua forma execução delegada a uma organismo da sociedade civil - no caso à ONG UEVOM - se configura como retrato das novas relações Estado e sociedade civil no projeto de sociabilidade neoliberal de terceira via (MELO, 2005).

A VOM é uma instituição pública - embora administrada por uma ONG - onde são oferecidas práticas esportes e atividades físicas, além possibilitar a vivência de outras manifestações de lazer para os moradores da Favela da Maré. Contudo, neste texto nos ocuparemos de uma dimensão específica de sua atuação no bojo das políticas públicas de esporte no Rio de Janeiro. Estamos falando da relação VOM e escolas do seu entorno, como parte das atividades desenvolvidas no seu âmbito. A partir de 2001, início da nova gestão de César Maia (2001-04) na PMRJ, é que são sistematizados mecanismos oficiais da referida relação Escolas-VOM. ${ }^{3}$

Com a entrada de um novo grupo político à frente da PMRJ (e da SMEL) em 2001, a dinâmica de funcionamento da VOM se altera de maneira significativa. Se antes a relação VOM e PMRJ se tratava de uma ação restrita mais ao financiamento, podemos afirmar que o novo grupo a concebe como parte central das políticas públicas de esporte em favelas do município. Mais do que isso, foi considerada uma espécie de projeto piloto de uma iniciativa que se espalhou ao longo do mandato do Prefeito César Maia (e uma das principais peças de sua campanha pela reeleição em 2004) - os programas de esporte e lazer em favelas e bairros pobres, conhecidas como Vilas Olímpicas. A VOM passa a fazer parte do projeto "Centros Esportivos de Ações Sócio Educacionais" (CEASE) da SMEL/PMRJ.

3 Apenas para registro estamos falando de duas instituições vinculadas a duas pastas diferentes; a VOM vinculada à Secretaria de esporte e lazer (SMEL), e as pastas diferentes; a VOM vinculada à Secretaria de
Escolas vinculadas à Secretaria de Educação (SME).

Movimento, Porto Alegre, v. 11, n. 3, p. 89-106, setembro/dezembro de 2005 
Como forma de sistematizar a relação VOM e Escolas são produzidos dois documentos - aparentemente independentes -, que nos ajudarão a compreender os elementos vivenciados na prática cotidiana da relação VOM e escolas. Tanto no projeto "Maré Integração Escolar", feito pela equipe da VOM (UEVOM, 2000a), como no projeto CEASE, pela equipe da SMEL (TAVARES \& MARA, 2001), encontram-se pontos em comum que levam, mais uma vez, a comprovar a confluência das duas concepções.

Ambos apontavam a necessidade de que o Centro Esportivo - no nosso caso a VOM - estabelecesse relações com a rede municipal de Educação, partindo do princípio de que a prática esportiva poderia atuar como forma de melhorar alguns índices escolares, sobretudo, no que se refere à evasão e o rendimento escolar dos alunos e que as escolas não disporiam das condições para atender essa demanda esportiva, pela inexistência de instalações e profissionais, já que os professores de Educação Física atuariam apenas com as turmas. Outro ponto em comum é a aposta na possibilidade do esporte ser um importante mecanismo de enfrentar o envolvimento juvenil com crime, seja por poder “... contrapor-se aos apelos da marginalização" (UEVOM, 2000a, p. 04), ou então, atuando de forma a "... enfrentar e enfraquecer os agentes do estresse social que deformam a conduta e marginalizam nossa juventude" (TAVARES \& MARA, 2001, p. 01).

Outra significativa coincidência/confluência entre os dois documentos está no fato de que ambos bradam pela necessidade de "retirar as crianças e jovens das ruas" e da "ociosidade". Com linguagens aparentemente diversas, expressam a mesma idéia, de que a criança/ jovem pobre precisa ser afastada do convívio com o tráfico, violência, já que estes teriam quase como destino manifesto o envolvimento com o tráfico. No documento da UEVOM, justifica-se sua relevância por trabalhar com a "formação dos cidadãos do futuro", onde os esportes poderiam atrair muitos jovens, permitindo que:

enquanto a questão econômica e social global não estiver plenamente resolvida, os jovens sem perspectivas evitem os descaminhos, supostamente cativantes, mas que os levarão a uma vida marginal de menor significado na sociedade e a uma menor consciência de seus direitos, deveres e potencialidades (2000a, p. 3).

Já no projeto CEASE da SMEL, explicita-se que ao oferecer aos jovens e crianças dos bairros pobres, acesso à prática esportiva e um contato mais prolongado com a Escola, que deles deveriam tomar conta, seria “... possível afirmar estar retirando-os do campo psicológico de muitos de seus agentes estressantes, minimizando seus efeitos se que, contudo, os desvincule de sua realidade social"

Movimento, Porto Alegre, v. 11, n. 3, p. 89-106, setembro/dezembro de 2005 
(TAVARES \& MARA, 2001, p. 04). Em ambos, grassa uma visão salvacionista de se pensar o papel das políticas de esporte. Ou então, uma forma mais palatável de expressar as idéias de controle social através das práticas corporais, sobretudo, o esporte. Faz-se presente não uma concepção de ampliação de acesso a direitos sociais, mas sim medidas supostamente "profiláticas", que minimizariam as chances dos jovens seguirem os caminhos do tráfico de drogas (MELO, 2005).

Além das aulas de Educação Física enquanto disciplina curricular, os estudantes também teriam aulas nos Centros Esportivos. Ou seja, embora fosse um centro de Lazer, a relação com a Escola transcendia a relação de necessária proximidade no sentido de conhecer tanto os alunos como suas realidades. Vinculava-se também aos mecanismos na garantia de freqüência aos Centros, já que, as crianças vindas diretamente das escolas teriam participação compulsória, e não precisariam se inscrever para participar seja por vontade própria ou de seus pais. Passava a ser uma decisão da escola. É preciso ressaltar que estamos falando da participação dos alunos durante seu turno de aula, e não como complementar em outro turno. Mais do que apontar eventuais ou supostas inconsistências dos documentos importa saber que tais orientaram os encaminhamentos da VOM.

No caso da VOM essa aproximação também teve outra razão de ser. Mesmo considerando as poucas possibilidades de lazer existentes na Maré para crianças e jovens, foi preciso recorrer a essas ações com as escolas "... para melhorar a freqüência" (UEVOM, 2000a). Assim, fica claro que, além de todos os objetivos apontados, tais ações conjuntas - VOM/Escolas - estiveram imbuídas da missão de garantir o quorum apresentado nos balanços mensais e relatórios apresentados à PMRJ e à Petrobrás. Recorreu-se continuamente a essa freqüência para que a VOM sempre aparentasse estar cheia.

Aliás, a questão do quantitativo real da VOM sempre foi algo controverso. A prática cotidiana como professor da instituição indicava que os números oficiais divulgados não condiziam com a realidade. Quando eram publicadas reportagens nos jornais afirmando ter a VOM por volta de 9000 alunos, poder-se-ia dizer que esse não era o dado concreto do dia-a-dia. Mas, por quê então essa hiperplasia no quantitativo? De onde partiam esses dados? A quem interessavam?

Analisando documentos da VOM, e também as informações obtidas nas entrevistas com os atores envolvidos no processo, notase ter ocorrido uma significativa dificuldade de justificar o quantitativo apresentado nos documentos. Não por acaso o mecanismo dos convênios com as Escolas foi pensado para trazer as crianças para a VOM.

Movimento, Porto Alegre, v. 11, n. 3, p. 89-106, setembro/dezembro de 2005 
Frente a esses números, um dos principais participantes do processo afirma que:

uma das coisas mais sérias ainda, é que a ONG passou uma informação para a

SMEL de que ali naquele momento se atendiam 5.000 pessoas. E sabíamos que isso não era verdade. Mas tínhamos que encher aquilo. (...) Aí no $1^{\circ}$ mês de trabalho, quando fui fazer meu $1^{\circ}$ relatório começaram os problemas, já que só tinham 1170 pessoas freqüentando. Aí perguntamos o que fazer ao responsável da SMEL. Então tinha seguinte maquiagem: 5.000 alunos inscritos e 1.170 freqüentando. Aí começamos a estabelecer metas para chegarmos a 5.000 pessoas em dezembro pelo menos. Aí trabalhamos de maio a dezembro de 2001 com essa meta. Nós conseguimos. Aí tínhamos outra questão nos relatórios 10.000 inscritos e 5.000 freqüentando. Isso era muito triste porque a ONG precisava mostrar números para a Petrobrás, já que precisava justificar o financiamento, o investimento. E tinha que mostrar número a SMEL (Entrevistado E).

Então como forma de enfrentar isso, foi preciso encher rapidamente a VOM de crianças, já que com a entrada dos novos profissionais em maio de 2001, seria preciso justificar o investimento. ${ }^{4}$ Assim, buscou-se o mecanismo de convênios com as escolas da região, sobretudo, os quatro CIEPs vizinhos. ${ }^{5} \mathrm{Na}$ verdade, esse contato se deu via $4^{\text {a }}$ Coordenadoria Regional de Ensino (CRE), através de sua Diretora, que parece ter ficado muito empolgada;

ela achou super legal e deu todo apoio e ela fez um documento para as diretoras dizendo que seria muito importante levar as crianças na VOM, quase que dizendo ser obrigatório. Independente desse contato com a CRE, o apoio quase total de sua diretora, fomos a todas as escolas da Maré para levar o Folhetim da

VOM dizendo o que era o projeto, porque é importante a criança ir lá, o que tem lá para ser oferecido, e dar uma real visão do que é a VOM (Entrevistado C).

Fica explícito nessa passagem, que mais do que uma relação Centro Esportivo-Escola, trata-se uma face da política pública de educação e esporte no município. Um projeto de governo, com determinação de cima para as escolas cumprirem.

Defendia-se que, recebendo os alunos das escolas, estar-se-ia atendendo crianças e jovens da Maré, já que os estudantes são seus moradores. Com isso, além das aulas de Educação Física nas escolas,

4 "Mas tínhamos que encher aquilo. E precisávamos de alguém para encher aquilo, e alguém que fizesse essa interlocução com as escolas, com as CREs, que fizesse esse caminho"."(Entrevistado E)

5 Todos são CIEPs Municipalizados. São eles CIEP Operário Vicente Mariano (Baixa do Sapateiro); CIEP Samora Machel e CIEP Elis Regina (divisa Baixa do Sapateiro e Nova Holanda). Embora bem menos freqüente, também vinham turmas do CIEP Hélio Smidt, que fica na Nova Holanda, exatamente ao lado $22^{\circ}$ Batalhão de Polícia.

Movimento, Porto Alegre, v. 11, n. 3, p. 89-106, setembro/dezembro de 2005 
esses alunos vinham uma vez por semana para a VOM ter "aulas" de esporte, como já apontava os projetos CEASE e MARÉ INTEGRAÇÃO ESCOLAR.

Esses estudantes seriam incorporados às turmas regulares das diversas modalidades. Isto se mostrou impraticável, já que cada professor receberia, além dos que já estivessem em suas aulas, todo o conjunto de estudantes das turmas determinadas, o que provocaria um inchaço nas aulas para além do possível. Então, começou-se a atender turmas completas, e a cada professor e/ou estagiário era delegada à "aula".

É interessante perceber a dimensão pedagógica dessas aulas. Até praticamente o último bimestre de 2001 não havia uma definição professor/turma, ou seja, a turma viria para a VOM e seria assumida por um professor (ou mesmo estagiários). As turmas não tinham professores fixos, dificultando as possibilidades de intervenção pedagógica.

A despeito dos objetivos apresentados nos programas, fica a impressão que era mais significativo o fato de ter a VOM cheia, com muitas crianças nas quadras, do que o que realmente se fazia. ${ }^{6}$ Assim, a ida a VOM tornava-se um mecanismo que os professores das Escolas usavam para exigir "bom comportamento" dos alunos: só iriam para a Vila Olímpica as turmas que se comportassem. Assim, a ida a VOM tornava-se um "prêmio" pelo bom mocismo dos alunos!

Isso não quer dizer que relações entre Escolas e Centros Esportivos de Lazer não devam ocorrer. Contudo, é preciso garantir as especificidades institucionais. Como um projeto de lazer, a VOM não deveria receber os alunos no tempo escolar e sim após esse. Não com o argumento de afastar criança das ruas, das drogas ou coisas parecidas, mas por compreender que a vivência do esporte, das artes, da dança, de música e outras práticas culturais são elementos indispensáveis à formação humana, implicando num projeto educacional ampliado. Não por seu "potencial salvacionista"; não por ser um disciplinador da infância e juventude mas por ser um direito de fruição cultural do/no lazer.

6 "O objetivo do trabalho não era só encher a VOM. Não era só isso que justificativa a vinda dos CIEPS. Tudo bem, nós tínhamos algumas parcerias que poderiam estar, como qualquer outro parceiro, exigindo que o projeto funcionasse. E a contrapartida do projeto funcionar é termos um número maior de alunos. Inicialmente, partida do projeto funcionar é termos um número maior de alunos.

Movimento, Porto Alegre, v. 11, n. 3, p. 89-106, setembro/dezembro de 2005 
A despeito dessas questões, a SMEL parece ter aprovado esse tipo de relação entre Escola e Centros Esportivos, estendendo aos outros Centros Esportivos/Vilas Olímpicas. Com isso, a pessoa que fazia a ligação com VOM-Escolas, é convidada desempenhar tal função no interior da SMEL, abarcando todo o conjunto de Vilas Olímpicas, já que estas “... estavam com problema muito sério do número de freqüência. Eu fui para a SMEL fazer esse tipo de trabalho" (ENTREVISTADO E).

Entretanto, o caráter conformador e educativo em sentido ampliado, se manifesta na transposição de que estes projetos esportivos atenderiam às demandas da população, que expressaria isto freqüentando em massa aos Centros Esportivos. Mas, face ao já descrito anteriormente, esse "sucesso de público" pode ser facilmente contestado, uma vez que em grande parte tratava-se dos alunos das escolas com participação compulsória.

Seria de estranhar o fato dessa gritante contradição entre os números apresentados e o que a realidade apresentava nunca ter chamado a atenção da PMRJ e da Petrobrás. A razão dessa "não suspeita" quantos aos números oficiais do projeto é apresentado na fala de um entrevistado:

A SMEL não ficou preocupada com o que acontecia lá dentro. Só queria um número para projetar politicamente. Só isso. Um número de propaganda. Agora, se realmente lá tinha 2.000, 5.000, 10.000, não estava interessada nisso. Queria aquele número para contar. E aí os relatórios iam com os números feitos que a SMEL estavam precisando. Infelizmente. Muito duro de falar isso, mas é a verdade. Interessava todo mundo. Interessava a nós enquanto Coordenação técnica para se manter, interessava a UEVOM para continuar a se manter e receber as Verbas da SMEL; interessava a SMEL para continuar falando que ali dentro tinha 15000. Chegaram a falar que ali tinha 15000 (Entrevistado E).

Esta última fala revela que não era de interesse de nenhum dos grupos envolvidos problematizar ou questionar essa questão. Essa confluência de projetos políticos e concepções de mundo corroborou na conformação ético-política da VOM como expressão da nova configuração das políticas públicas. Com isso, sua face educativa se apresentava para além das mediações pedagógicas estabelecidas em seu interior, ainda que estas apresentassem contradições com a própria imagem que a VOM tem na sociedade.

Pode-se dizer que durante os anos de 2001 e 2002 os jovens e crianças advindas com as escolas eram responsáveis pela garantia do quantitativo na VOM. Tanto que quando não havia aulas nas escolas a VOM ficava vazia.

Movimento, Porto Alegre, v. 11, n. 3, p. 89-106, setembro/dezembro de 2005 
Somente no ano de 2003 é que a freqüência das escolas tendeu a diminuir, já que a VOM conseguiu efetivamente justificar o quantitativo apontado. Contudo, isso não quer dizer que não se fizessem presentes, apenas não eram mais responsáveis por mais da metade dos praticantes. A VOM podia apresentar-se, majoritariamente, como um projeto de lazer. A partir de nossos relatórios mensais, também da própria experiência visual, era possível atestar esse aumento real do quantitativo. Esses relatórios eram, na verdade, pautas com os nomes dos alunos, a idade, a "comunidade" e a escola. Assim, "nós chegamos finalmente na segunda metade de 2003 a poder provar que realmente tínhamos 11000 alunos" (Entrevistado F). Contudo, isso não implica que sejam 11.000 pessoas diferentes, já que era comum haver alunos inscritos em mais de uma modalidade, indo para o banco de dados como duas inscrições, embora se trate da mesma pessoa! Não obstante, muitos alunos que vinham com suas escolas em um turno, voltavam a tarde por conta própria, o que poderia indicar duas inscrições.

Mais isso pouco importa, visto que no imaginário popular as Vilas Olímpicas no Rio de Janeiro seriam espaços de práticas esportivas e de lazer que todo o conjunto da população estaria recebendo e freqüentado em massa. Não por acaso, esse mecanismo de relação Vilas Olímpicas-Escolas não ficou restrito a VOM, sendo usada também outras com "problemas" de freqüência, ou seja, para justificar a pouca presença de freqüentadores, ainda que pese o fato de estarem localizadas em bairros pobres e favelas, onde as opções de lazer e esporte seriam poucas. Ainda assim, não foi possível obter o consenso passivo da população. Será que a população pobre está demonstrando, mais uma vez, aos governos populistas que "saco vazio não pára em pé"?

\section{Disputa de pênaltis ou considerações finais}

A relação VOM-escolas mostrou-se um importante mecanismo de obtenção do consenso popular em torno do projeto. Não se trata aqui de julgamento moral, e sim a compreensão política desse mecanismo de convencimento, já que transpassa a imagem para o conjunto da população que havia ampla aceitação da VOM como resposta a reais necessidades dos moradores da Maré.

Tais questões aqui apresentadas nos dão pistas de como a relação Escola e lazer foi concebida no bojo das políticas públicas de educação e esporte lazer no município do Rio de Janeiro. Mais do que ampliar as possibilidades de lazer dos alunos da rede municipal

Movimento, Porto Alegre, v. 11, n. 3, p. 89-106, setembro/dezembro de 2005 
de educação, tendo as Vilas Olímpicas como lócus para isso, devido à existência de estrutura física para tal, temos nesse caso mecanismos de precarização tanto da educação escolar como também da vivência esportiva como lazer.

Menos do que a discussão acerca do real quantitativo da VOM fica a questão de como o bloco no poder busca utilizar o esporte e lazer como estratégia educativa do conjunto da população para não problematização do contexto das relações sociais em que estão inseridas. Isso se expressa na indicação de tais mecanismos foram respaldados, de certa forma, pelo grupo a frente da SMEL/PMRJ, já que assim haveria a indicação de que o programa VOM é um sucesso. Ainda que fosse notório o esvaziamento da VOM não havia hesitação em divulgar um transbordar de crianças e jovens com participação nas atividades.

A VOM se concretiza enquanto um importante mecanismo de obtenção de consenso popular na medida em que serve para divulgação de projetos com concepções de mundo que não levam a problematização crítica das difíceis condições de vida, não apenas na Maré, mas na sociedade em geral.

De modo algum pretendemos afirmar que a VOM não teria nenhuma importância para aqueles que a freqüentavam, mesmo sendo parcela diminuta do universo de pessoas da Maré. Contudo, esse caráter mítico, quase religioso de "salvação", de resolução de todas as questões sociais apenas por sua existência, representa essa face de obtenção do consenso e repolitização para o não enfrentamento crítico do atual estado de coisas. Se, indubitavelmente, representa maiores possibilidades de opções de lazer e esportes para os freqüentadores, é preciso apontar que não cabe nenhuma associação direta e linear com possíveis melhorias gerais das condições de vida da população. Tal questão nos leva a pensar que se o acesso ao esporte e ao lazer é fundamental, não são suficientes, para uma efetiva melhoria nas condições de vida.

A relação Lazer e escola pode contribuir para o desenvolvimento e qualificação da vivência de ambos. Tanto as práticas de lazer, como as práticas escolares trazem em si possibilidades de encontro com a riqueza da produção cultural da humanidade. Ainda que considerando a especificidade de cada momento/instituição, pensamos em intervenções que possam potencializar a capacidade que ambas apresentam para um projeto educativo crítico e criativo, sobretudo na educação das diversas frações e grupos sociais da classe trabalhadora. E justamente isso não se

Movimento, Porto Alegre, v. 11, n. 3, p. 89-106, setembro/dezembro de 2005 
fez presente na Vila Olímpica da Maré. Longe de ser fruto de incompetência, tal questão expressa contornos lúcidos do projeto de sociedade contemplado a partir do funcionamento da VOM.

The Vila Olímpica da Maré and the public policyes of sports from Rio de Janeiro: talking about the relationship schools, sports and leisure

Abstract: this text seeks to discuss the relationship between Vila Olímpica da Maré (VOM) and some schools, in its trajectory of implementation like a public policy of sports and leisure at Rio de Janeiro City. Which conceptions of education, sport and leisure can be observed in this project? How's the VOM relationship with the schools? What are the pedagogical-political dimensions for that encounters?

Keywords: Education, Leisure, Sports and Vila Olímpica da Maré.

La villa olímpica de la Maré y las políticas publicas del Deporte de Rio de Janeiro: debatiendo la relacion escuela, deporte y ocio

Resumen: A partir de lo debate de la dimensión educativa en las practicas de ocio, lo presente texto busca discutir como se fue dado la relacción Villa Olimpíca de la Maré (VOM) y las escuelas que si relacionavam com ella en lo proceso de ejecución de esta plítica publica del deporte y ocio de la Prefectura de Rio de janeiro. ¿Como se han dado las relaciónes entre escuelas y VOM? ¿Que concepciónes de educación estuvieram presentes en esto proceso? ¿Cual la dimensión político-pedagógica de estos encuentros?

Palabras-clave: Ecucación, Ocio, Deporte, Villa Olímpica de la Maré. 


\section{Referências}

ARROYO, Miguel. Trabalho - Educação e Teoria Pedagógica. In: FRIGOTTO, G. (org.). Educação e Crise do Trabalho. Perspectivas de final de século. Petrópolis; Vozes, 2002. pp. 138-164.

Educação em tempos de Exclusão. In: FRIGOTTO, G. \& GENTILI, P. A Cidadania Negada: Políticas de Exclusão na Educação e no Trabalho. São Paulo: Cortez, 2001, pp. 270-279.

CARRANO, Paulo. Juventude e Cidades Educadoras. Petrópolis; Vozes, 2003.

GRAMSCl, Antonio. Cadernos do Cárcere. Vol 2 e 3. Rio de Janeiro: Civilização Brasileira, 2001

JAMESON, Fredric. A Cultura do Dinheiro. Petrópolis: Vozes, 2001.

MASCARENHAS, Fernando. "Lazerania" também é conquista: tendências e desafios na era do mercado. Movimento/UFRGS, Porto Alegre, V. 10, $\mathrm{n}^{\circ} 2 \mathrm{p} .73-$ 90, mai/ago 2004.

MELO, Marcelo Paula de. Esporte e Juventude Pobre: A Vila Olímpica da Maré e as Políticas Públicas de Lazer. Campinas: Autores Associados, 2005.

NEVES, Lucia M.W. (org.) A Nova Pedagogia da hegemonia: estratégias do capital para educar o consenso. São Paulo: Xamã; 2005.

PMRJ/SME. Secretaria de Educação. A Escola e a Família: A Prefeitura do Rio. Rio de Janeiro: SME/PMRJ, Ano 1, n 2 Set/2003

TAVARES, Sérgio \& MARA, Ellen. Projeto CEASE. Rio de Janeiro: SMEL/PMRJ. 2001. (mimeo).

UNIÃO ESPORTIVA VILA OLÍMPICA DA MARÉ. Projeto Maré Integração Escolar. Rio de Janeiro: UEVOM; Ano 1, n 16, Jan/2000a.

_.. Informativo UEVOM, Rio de Janeiro. Ano 2, n 20, Mai/2001a.

_. Informativo UEVOM, Rio de Janeiro. Ano 2, n 25/26, out/nov. 2001b.

Recebido em: 21.06 .05

Aprovado em: 25.11.05

** Mestre em Educação pela UFF. Professor do ISE-FAETEC (Três Rios) e da UNIABEU. Membro do Coletivo de Estudos de Política Educacional (UFF-FIOCRUZ).

Movimento, Porto Alegre, v. 11, n. 3, p. 89-106, setembro/dezembro de 2005 